\title{
The Journal of
}

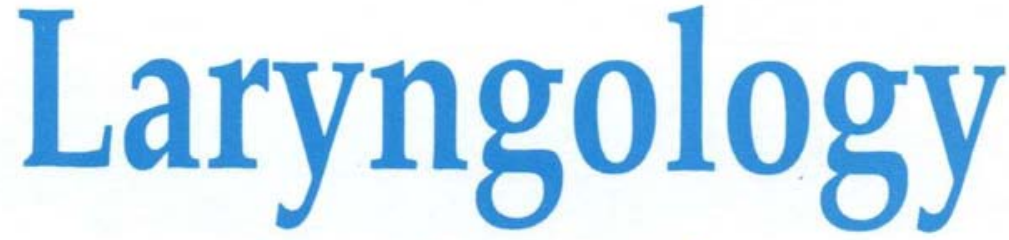

and Otology
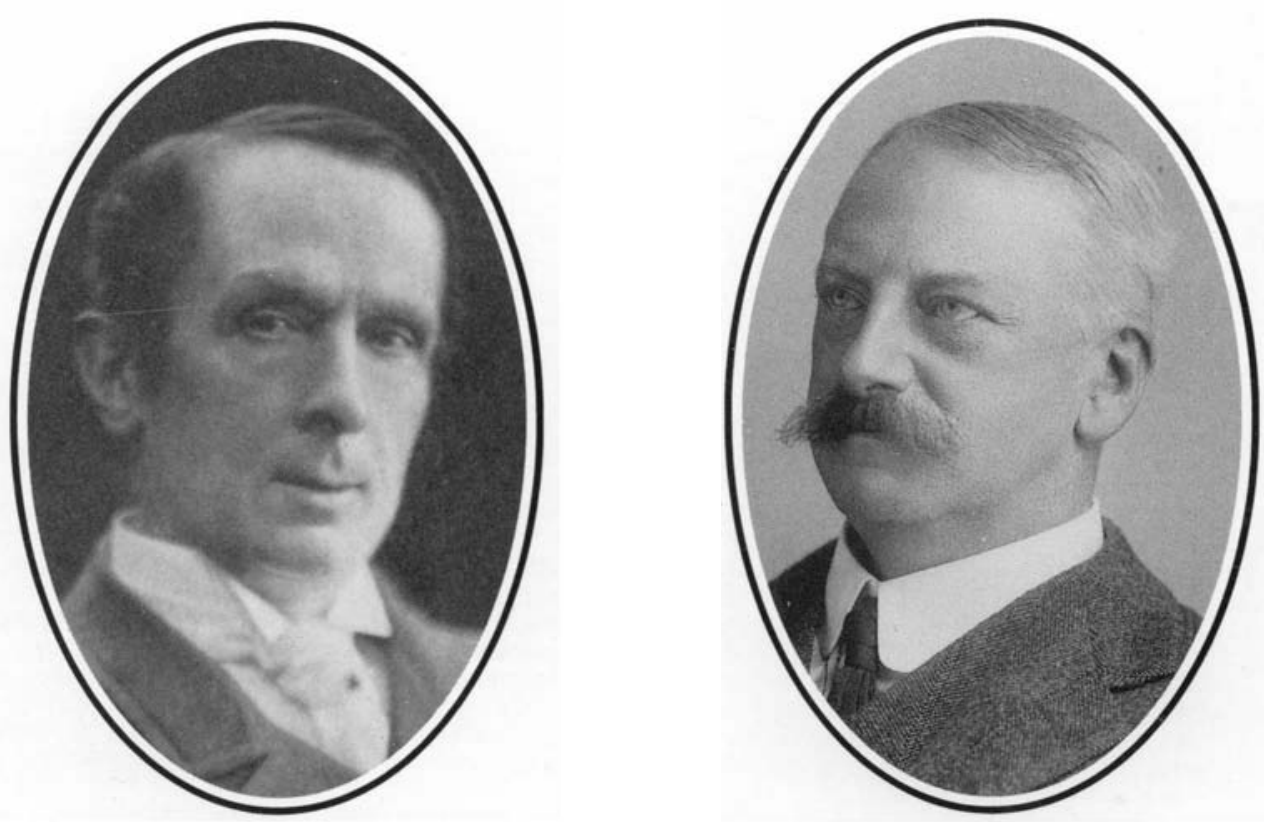

Founded in 1887 by Morell Mackenzie \& Norris Wolfenden

Edited by JOHN B. BOOTH

Assistant Editors NEIL WEIR, PATRICK BEASLEY, CAROL WENGRAF, RICHARD RAMSDEN, IOLO GRIFFITH \& PETER RHŶS EVANS

Advisor in Pathology IMRICH FRIEDMANN

Advisor in Audiology LINDA LUXON

Advisors in Radiology GLYN LLOYD \& PETER PHELPS

Advisors in Statistics ANTHONY HUGHES, PETER KELLY \& GILLIAN RAAB 


\title{
The Journal of Laryngology and Otology
}

\author{
(Founded in 1887 by MORELL MACKENZIE and NORRIS WOLFENDEN) \\ Edited by JOHN B. BOOTH \\ Assistant Editors NEIL WEIR, PATRICK BEASLEY, CAROL WENGRAF, RICHARD RAMSDEN, \\ IOLO GRIFFITH \& PETER RHŶS EVANS \\ INSTRUCTIONS FOR AUTHORS
}

1. Original articles which have not been published elsewhere are invited and should be sent to the Editor. They are considered for publication on the understanding that they are contributed to this Journa/ solely. Reproduction elsewhere, in whole or in part, is not permitted without the previous written consent of the Author and Editor and the customary acknowledgement must be made. Normally an original main article should not exceed 7500 words.

Longer articles or theses will be considered for publication as Supplements, at the expense of the authors or their employing authorities.

2. Manuscripts should be typewritten in duplicate on one side of the paper only (A4 $297 \times 210 \mathrm{~mm}$ ) and double spaced, with wide margins. Computer print-outs are not favoured.

Begin each component on a new page in the following sequence: title page, abstract, text, acknowledgements, references, tables and legends.

(a) Abstract-This should contain not more than 150 words and include a statement of the problem, the method of study, results and conclusions; a 'summary' section should not be included in the main manuscript.

(b) Key Words-only those appearing as Medical Subject Headings (MeSH) in the supplement to the Index Medicus may be used; where ro appropriate word(s) are listed those dictated by common sense/usage should be supplied.

(c) Text-Suggested outline-(1) introduction, (2) materials and methods, (3) results, (4) discussion, (5) conclusion.

(d) Tables are adjuncts to the text and should not repeat material already presented.

(e) Illustrations-Two sets of illustrations, one with each copy of the manuscript, must be submitted and all authors should remember that the single column width is $80 \mathrm{~mm}$. One set of illustrations should, therefore, not exceed this width and they should ensure that the essential features are illustrated within this dimension.

Coloured illustrations will be charged to authors, unless a special grant is authorized by the Editor.

Written permission from the publisher must be provided to the Journal in order to republish material with copyright elsewhere and also from the senior author where necessary.

(f) Measurements must be in metric units, with Système Internationale (SI) equivalents given in parentheses.

(g) References-For Journa/ articles, The Harvard system of recording references should be used, e.g. Green, C. and Brown, D. (1951). The tonsil problem. Journal of Laryngology and Otology 65: 33-38. A paper written by more than two authors should be abbreviated in the text, e.g. Green et al. (1951), but al/ the authors should be given in the list of references. The titles of all Journals should be given without abbreviation. References should be listed in alphabetical order; use of the Vancouver system will not be accepted.

For single-author books, the following style should be used: Green, C. (1951). The tonsil prob/em, 2nd edn., vol. 1, Headley Brothers Ltd., Ashford, Kent, p 33-38.

For papers in multi-author books with one or more editors, the reference should include the title of the chapter and the names of the editors, together with the number of the edition as eg: Brown, D. (1951) Examination of the ear. In Diseases of the Ear, Nose and Throat. 2nd Edition. (White, A., Black, B., eds.), Headley Brothers Ltd, Ashford, Kent, p 33-38.

It is most important that authors should verify personally the accuracy of every reference before submitting a paper for publication. The names of authors cited in the References should be given in alphabetical order.

(h) Meetings - If the manuscript was presented at a meeting, the place where it was held, and the date on which it was read must be included and should appear at the foot of the title page.

(i) Financial disclosures-In the submission letter to the Editor, the authors must list all affiliations with or financial involvement in, organizations or entities with a direct financial interest in the subject matter or material of the research discussed in the manuscript.

(j) Declaration. Each manuscript must be accompanied by a letter of declaration to be signed by each author to confirm that they have seen, read and approve the contribution bearing their name.

(k) Rejections-All manuscripts which are rejected will no longer be returned to the authors. Those submitting papers should, therefore, ensure that they retain at least one copy and the reference numbers, if any, of the illustrations The only exception to this will be those manuscripts with colour illustrations which will be returned automatically by Surface Mail.

(I) Facsimile (FAX). All authors should send a Facsimile number whenever possible to speed communication; this particularly applies to those outside the United Kingdom. Manuscripts with no visual illustrations (X-rays/pathology) may be sent by facsimile.

3. Page proofs are sent to authors for corrections, which should be kept to a minimum; they must be clearly marked, and no extra matter added. Proofs should be returned within 5 days.

4. Orders for reprints must be sent when returning page proofs, and for this purpose special forms are supplied.

5. Editorial communications may be addressed to The Editor, Journal of Laryngology and Otology, c/o Headley Brothers Ltd., The Invicta Press, Ashford, Kent TN24 8HH or sent by FAX (071-224 1645).

6. The annual subscription is $\mathbf{f 9 0 . 0 0}$ Institutions \& Libraries US\$225.00; $\mathbf{f 8 0 . 0 0}$ Individuals US\$200.00; $\mathbf{f 4 5 . 0 0}$ Registrars, Residents and Interns. (Those in training should submit a certificate from The Head of the Department giving details of their appointment; those who qualify must supply their home address for mailing direct). Claims to be made for missing issues within 6 months of each publication date.

7. Single copies of current or back numbers (when available) will be on sale at $£ 12.00$ each (including postage)

8. BINDERS to hold Journals for one year, available at $£ 12.00$ each.

9. SUPPLEMENTS published at 'irregular' intervals with subscription, available separately on request.

10. All subscriptions, advertising and business communications should be sent to the publishers, or subscription agents.

\section{HEADLEY BROTHERS LTD,}

THE INVICTA PRESS, ASHFORD, KENT.

(C) Journal of Laryngology and Otology Ltd., 1992

ISSN 0022-2151

Second class postage paid Rahway, N.J.

Postmaster: Send address corrections to The Journal of Laryngology and Otology, c/o Mercury

Airfreight International Ltd. Inc., 2323 Randolph Avenue, Avenel, N.J. 07001. Frequency of Publication: Monthly. 


\section{The AD 25 DIAGNOSTIC AUDIOMETER}

$$
\text { trom Kamplex }
$$

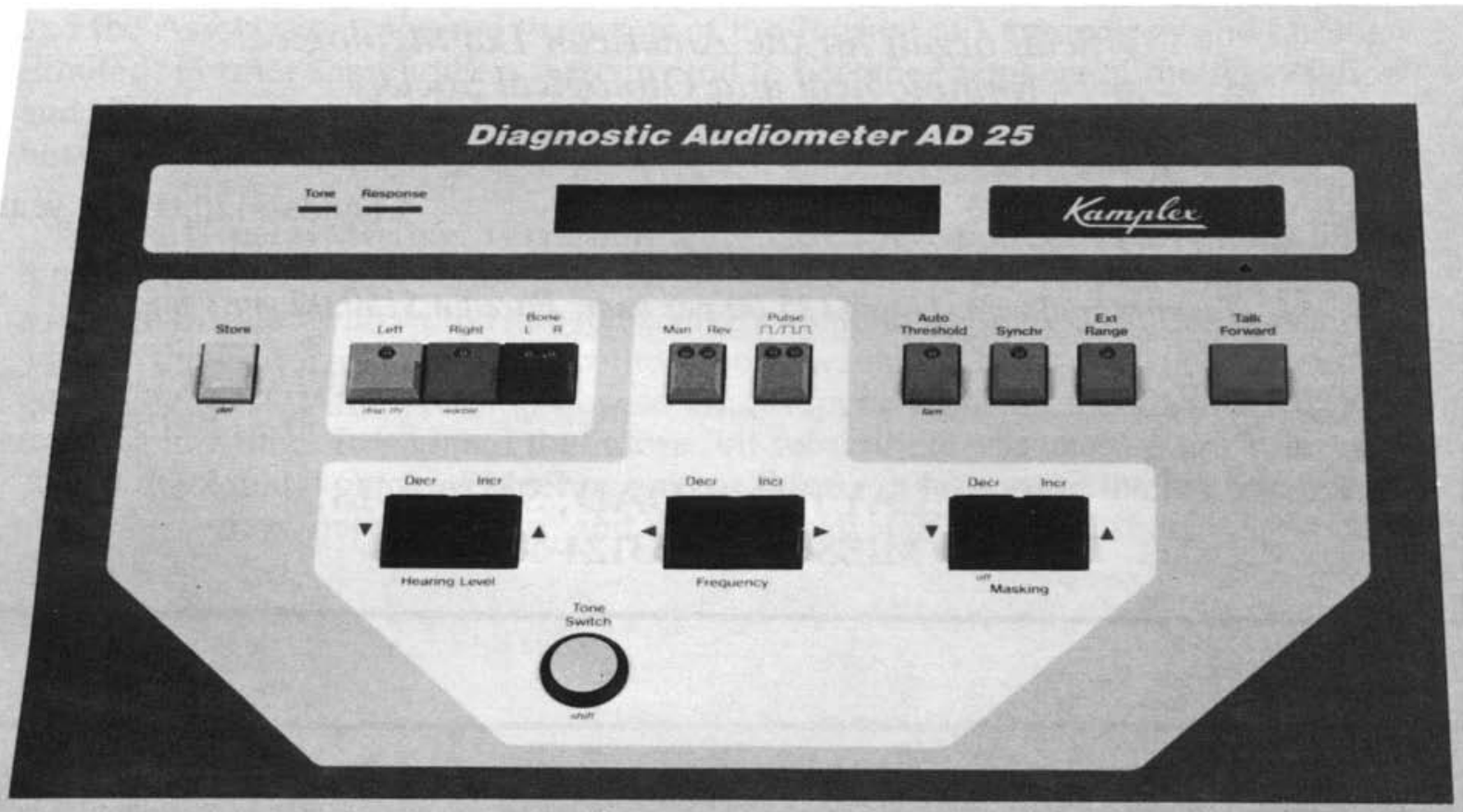

The latest addition to the Kamplex range incorporates many of the more popular features found on the best selling AD27 in a lightweight low cost package.

The attractive low profile design and easy-to-read back-lit display makes this a perfect desktop audiometer. Air Conduction, Bone Conduction and Narrow-band masking in $5 \mathrm{~dB}$ steps are available together with an extremely useful talk-through facility.

Superbly engineered for reliability and portability (with the optional case), the AD25 also offers an automatic test facility. A patient's audiometric results whether recorded manually or automatically may be stored and later recalled.

"Auto Threshold complies with ISO 8253, Audiometric Test Methods

\section{Robust and Portable (with optional carrying case)}

- $A C / B C /$ Narrow-Band Masking

- Pure, Warble and Pulsed Tones
- Clear, easy to read Back-lit Display

- Automatic Test Facility (Conforms to ISO 8253)

- Results Storage and Recall Capability

Insert Masking

\section{P.C.WERTH LTD}




\title{
THE LARYNGOSCOPE
}

\author{
A Monthly Journal \\ devoted to the disease of \\ EAR, NOSE AND THROAT \\ Official organ for the American Laryngological \\ Rhinological and Otological Society
}

Price $\$ 100.00$ per year

Canada $\$ 120.00$ per year

Foreign $\$ 120.00$ per year

Institutional rate: U.S. $\$ 125.00$ per year, Foreign $\$ 150.00$ per year

ESTABLISHED 1896

GERSHON J. SPECTOR EDITOR

\author{
9216 CLAYTON ROAD, ST LOUIS, \\ MISSOURI 63124-1561
}

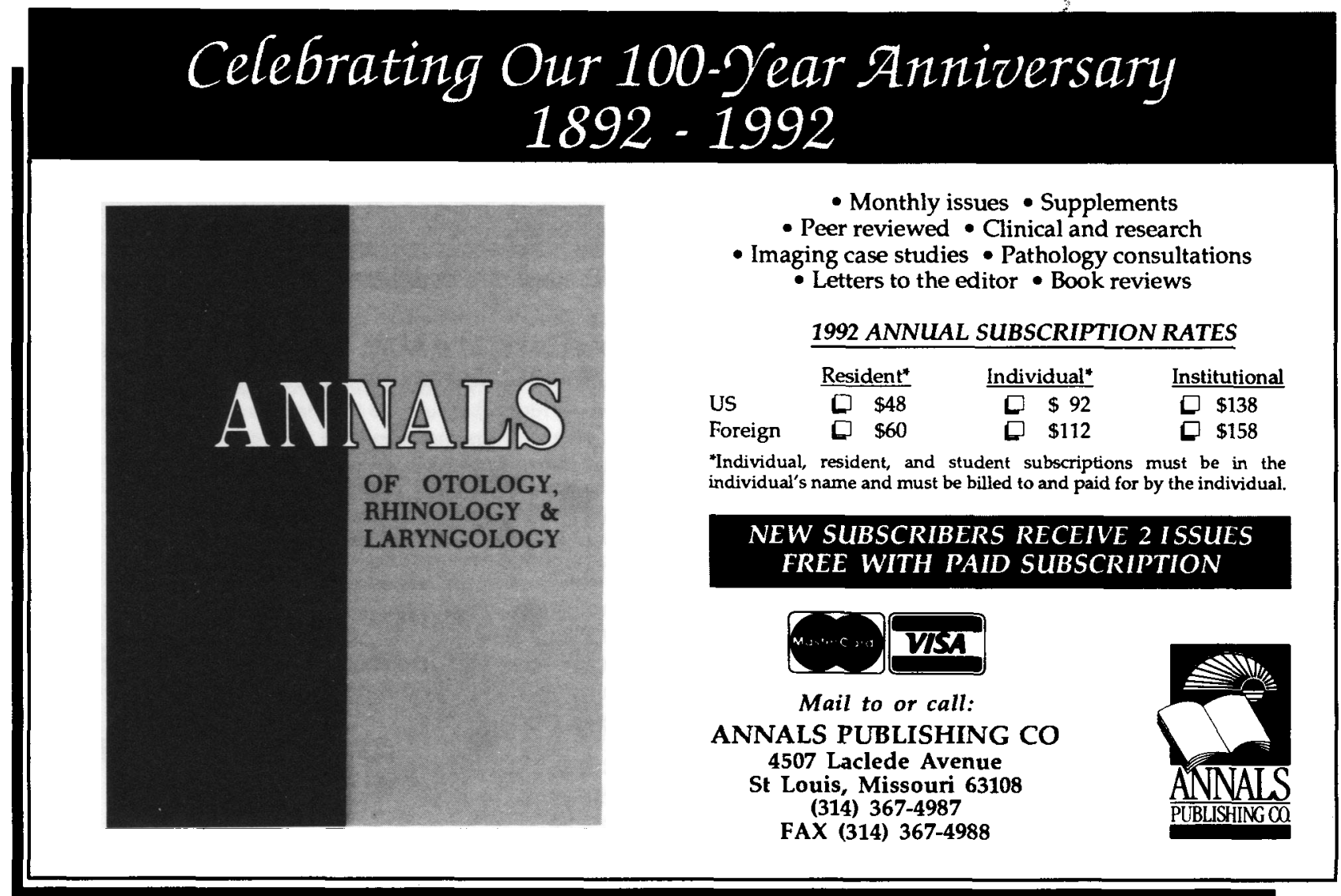




\title{
J.L.O. (1984) LIMITED \\ Company limited by Guarantee Reg No: 1865175 England
}

In 1984, The Journal ceased to become a Limited Company with shareholders and instead became a registered charity under the Companies Act, limited by guarantee and without having a share capital. A Memorandum of Association was drawn up and the Association acquired the assets of the Journal of Laryngology and Otology Limited. Former shareholders were invited to become members of the Association and all those who undertook to do so, gave a Guarantee that should the association need to be wound up, they would contribute a sum not exceeding $£ 20$.

Annual General Meeting. This is normally held each year in early November, and it is to the Members of the Assocition that invitations are issued. Any individual paying a full subscription who would like to become a member of the Association is asked to write to the Editor, c/o Headley Brothers, confirming that he or she will make such a guarantee of $£ 20$ if the occasion were to arise. Applications for membership may be made at any time. It is hoped that more full subscribers will take up this offer and attend the Annual General Meeting so that there can be a more lively exchange of views between them, and the Editorial staff and publishers.

\section{The Advertisement Manager}

\section{THE JOURNAL OF LARYNGOLOGY AND OTOLOGY}

\author{
Headley Brothers Limited \\ The Invicta Press \\ Ashford \\ Kent TN24 8HH \\ Tel: (0233) 623131
}




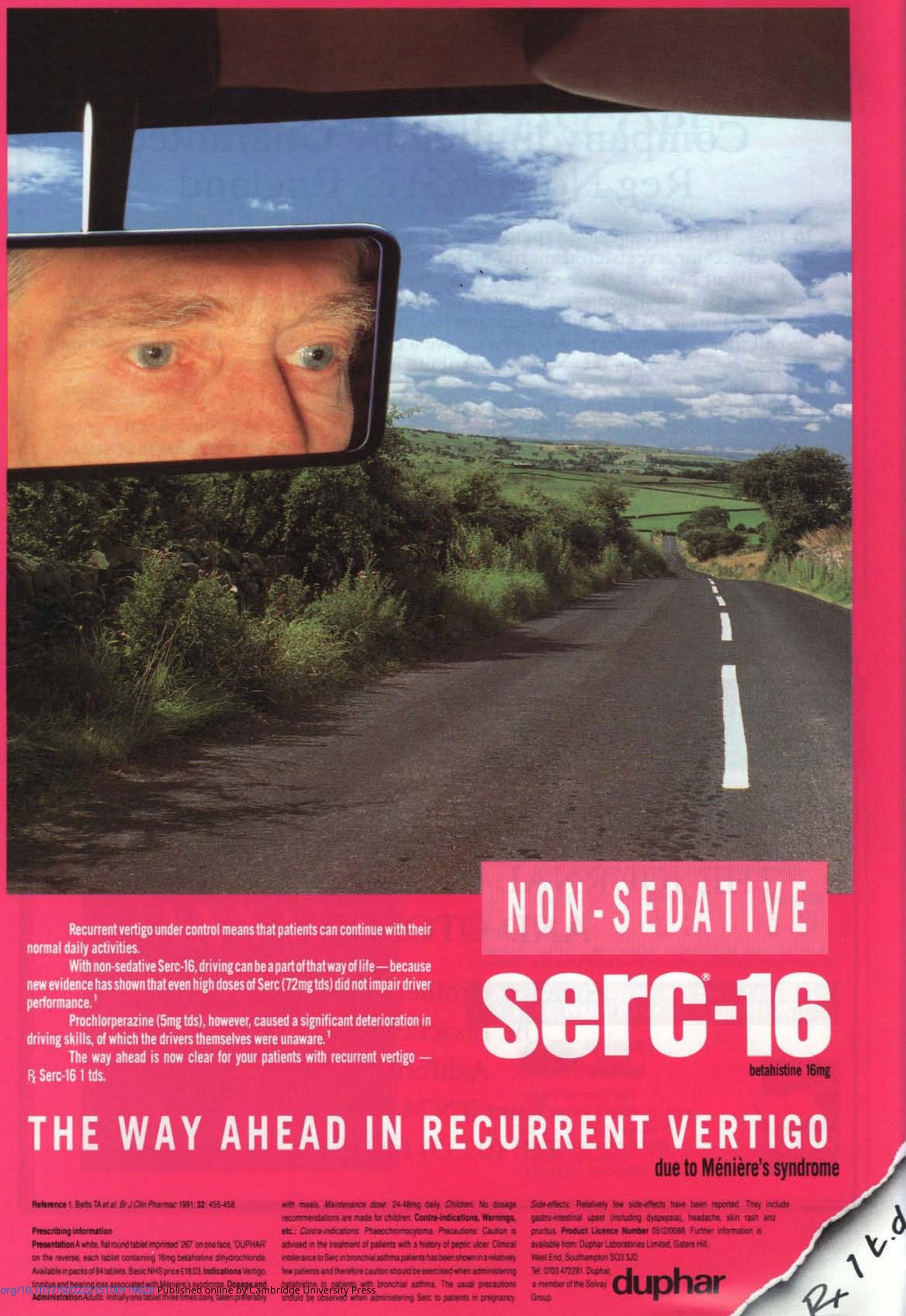

